\title{
Relationship between the Hospital Visit-to-Operation Time Interval and the Risk of Appendiceal Perforation and Clinical Outcomes
}

\author{
Seongmun Park, M.D., Min-Su Park, M.D., Ph.D., Kil-Yeon Lee, M.D., Ph.D. \\ Department of Surgery, Kyung Hee University School of Medicine, Seoul, Korea
}

Purpose: The aim of this study was to investigate the relationship between the elapsed time from hospital visit to operation and perforation risk and surgical site infection (SSI).

Methods: We conducted a single-center, retrospective cohort study using 986 patients who underwent appendectomy between Jan. 2009, and Dec. 2013. We divided hospital visit-to-operation time into multiple sessions and analyzed the statistical differences in univariate and multivariate analysis.

Results: Nine-hundred and ninety-six patients were admitted due to appendicitis and 986 (98\%) patients underwent an appendectomy. Perforation occurred in $13.2 \%(n=130)$ of these patients. Patients with greater than 12 hours of elapsed time between their visit to hospital and surgery demonstrated a higher perforation rate than those who underwent surgery within 12 hours from their visit to the hospital. Upon logistic regression analysis, appendectomy timing was a predictors of appendiceal perforation (adjusted odds ratio, 1.04; 95\% confidence interval, 1.00 1.07; $p=0.04$ ). The SSI rate of the patients who underwent appendectomy within $12 \mathrm{hrs}$ was lower than those who underwent surgery more after than 12 hrs, but hospital visit-to-operation time was not a statistically significant predicting factor of SSI (adjusted odds ratio, 0.99; 95\% confidence interval, 0.93 1.05; $p=0.796$ ).

Conclusion: A delay more than 12 hrs between the visit to a hospital and surgery was significantly associated with an increased risk of perforation of the appendix. However, it was not associated with an increase in the risk of SSI. Prompt surgical treatment is needed to decrease the risk of perforation.
Received September 2, 2017

Revised 1st October 16, 2017

2nd October 26, 2017

Accepted October 26, 2017

Corresponding author

Min-Su Park

Department of Surgery, Kyung Hee

University School of Medicine, 23

Kyungheedae-ro, Dongdaemun-gu,

Seoul 02447, Korea

Tel: $+82-2-958-8250$

Fax: +82-2-966-9366

E-mail: ikireida@hanmail.net

ORCID:

http://orcid.org/0000-0002-0707-2969

Keywords: Appendicitis, Perforation, Appendectomy timing, SSI

This is an Open Access article distributed under the terms of the Creative Commons Attribution Non-Commercial License (http:// creativecommons.org/licenses/by-nc/4.0/) which permits unrestricted non-commercial use, distribution, and reproduction in any medium, provided the original work is properly cited.

Copyright (C) 2018 The Journal of Minimally Invasive Surgery. All rights reserved.

\section{INTRODUCTION}

Acute appendicitis (AA), which has a high lifetime incidence in general population, is one of the most common diseases that require emergent surgical treatment. Without immediate intervention, appendicitis can progress to appendiceal perforation with intraperitoneal contamination, which can cause complications such as peritonitis or abscess formation and may lead to prolonged hospital management. Hence, to prevent potentially significant morbidities, complete surgical excision of the inflamed appendix before rupture is important. ${ }^{1-7}$

Many recent studies have emphasized the importance of preventing appendiceal perforation. In particular, the time interval between hospital visit and surgery is one of the factors that can be objectively quantified and has been analyzed in many prior articles. However, the acceptable in-hospital time 
before surgical treatment that can minimize complication rates remains controversial. ${ }^{8-27}$

Many surgeons have stated that appendectomy should be performed without delay, irrespective of the time of day. They emphasize that longer hospital visit-to-operation time increases perforation risk. ${ }^{8-13}$ However, several previously published retrospective series have reported conflicting relationships between the timing of surgery and the risk of morbidities. These studies reported that appendectomy timing was not associated with the risk of perforation. In addition, a common limitation of previous research was obscurity regarding the timing of appendiceal perforation, especially "before arrival to hospital' or 'while waiting for surgery in hospital. ${ }^{14-27}$

The aim of this study was to investigate the relationship between elapsed time from hospital visit to operation and perforation risk and surgical site infection (SSI) in patients that were radiologically diagnosed with appendicitis with no evidence of perforation at a single medical center.

\section{MATERIALS AND METHODS}

\section{Patients and data collection}

A retrospective medical chart review of all patients who underwent an appendectomy from January 2009 to December 2013 at a single center (OO University Hospital in Seoul, Korea) was conducted. Data on clinical condition, surgery, morbidity, and timing of surgery were collected by reviewing the medical records. During this period, 996 patients visited the hospital due to appendicitis and routine radiological investigations, such as ultrasonography or computed tomography, were performed during the diagnostic process. Among them, 988 patients with no radiological evidence of perforation underwent appendectomy. Six patients were excluded because they did not undergo surgery after their diagnosis, and two patients were excluded since their pathological reports showed that they were misdiagnosed.

\section{Variables and outcome}

Collected patient characteristics included age, sex, white blood cell (WBC) count, American Society of Analgesia (ASA) score, time of admission and operation, operation method (laparoscopy vs open conversion), and the time interval between the hospital visit and operation. The hospital visit-tooperation time delay was defined as an interval from the time that a patient arrived to the hospital to the time that the operation started. We divided hospital visit-to-operation time into multiple session; 6 hrs, 6 12 hrs, 12 24 hrs, over 24 hrs, and analyzed the statistical difference. To elucidate the risk factors of appendiceal perforation and SSI, we analyzed multivariate analysis. Perforated appendix was diagnosed primarily intraoperatively and confirmed on histopathological examination. The diagnostic criteria for perforated appendix included followings: visible perforation, spilling of feces.

\section{Statistical analyses}

Continuous data are described as the mean (standard deviation, S.D.) and median (range), with analysis done by Student's t-test. The significance of differences between groups of cat-

Table 1. Characteristics of patients $(\mathrm{N}=986)$

\begin{tabular}{|c|c|}
\hline Variable & Total $(N=986)$ \\
\hline Age (years), mean $\pm S D$ & $34.2 \pm 18.6$ \\
\hline Age over 50 years old, $\mathrm{n}(\%)$ & $225(22.8)$ \\
\hline \multicolumn{2}{|l|}{ Sex } \\
\hline Male, n $(\%)$ & $527(53.4)$ \\
\hline \multicolumn{2}{|l|}{ ASA class } \\
\hline 1 & $564(57.2)$ \\
\hline 2 & $399(40.5)$ \\
\hline$\geq 3$ & $23(2.3)$ \\
\hline Length of hospital stay (days), mean \pm SD & $4.3 \pm 2.8$ \\
\hline WBC count (on admission) & $12,885 \pm 5,737$ \\
\hline Night hospital visit, n (\%) & $172(17.4)$ \\
\hline Night admission, $\mathrm{n}(\%)$ & $217(22.0)$ \\
\hline Night operation, n $(\%)$ & 37 (3.8) \\
\hline Operation time (min) & $58.0 \pm 27.4$ \\
\hline Visit-to-operation (hr), Mean \pm SD & $9.4 \pm 5.8$ \\
\hline \multicolumn{2}{|l|}{ Visit-to-operation, n (\%) } \\
\hline Within $6 \mathrm{hr}$ & $353(35.8)$ \\
\hline $6 \sim 12 \mathrm{hr}$ & $358(36.31)$ \\
\hline $12 \sim 24 \mathrm{hr}$ & $258(26.17)$ \\
\hline Over $24 \mathrm{hr}$ & $17(1.72)$ \\
\hline \multicolumn{2}{|l|}{ Visit-to-operation, n (\%) } \\
\hline Within $12 \mathrm{hr}$ & $711(72.11)$ \\
\hline Over $12 \mathrm{hr}$ & $275(27.89)$ \\
\hline Perforation, n (\%) & $130(13.2)$ \\
\hline Laparoscopic appendectomy, n (\%) & 978 (99.2) \\
\hline Open conversion, n $(\%)$ & $7(0.7)$ \\
\hline Appendectomy & $960(97.4)$ \\
\hline Drain insertion & $261(26.5)$ \\
\hline
\end{tabular}


egorical variables was tested using the $\chi^{2}$ test. The significance level was set at $p<0.05$. Then, statistically significant factors were selected and a logistic regression model was developed.

\section{RESULTS}

\section{Patient characteristics}

Over 5 years, 996 patients with appendicitis visited OO University Hospital, and 986 (98\%) patients underwent appendectomy for acute appendicitis. The mean age was $34.2 \pm 18.6$ years, and the proportion of patients over the age of 50 was $22.3 \%(n=225)$. Of the 986 patients, 53\% ( $n=527)$ were male and the mean WBC count was $12,885 \pm 5,737$. Most patients were classified as American Society of Anesthesiologist (ASA) class 1 or $2(97.5 \%)$. The mean operation time was $58.0 \pm 27.4 \mathrm{~min}$, and the average time delay from hospital visit to operation was $9.4 \pm 5.8$ hour. On pathology, $13.2 \%$ ( $n=130)$ of patients had perforated appendix. $99.2 \%$ of patients underwent laparoscopic appendectomy, and open conversion was done in $0.7 \%$ of cases (Table 1).

\section{Comparison between the 'non-perforation' and 'perforation' groups}

The mean age of patients was $33.1 \pm 18$ and, $41.8 \pm 20.7$ years

Table 2. Comparison of characteristics between non-perforated and perforated groups

\begin{tabular}{|c|c|c|c|}
\hline Variable & Non-perforation $(\mathrm{N}=856)$ & Perforation $(N=130)$ & $p$ value \\
\hline Age lyears), mean $\pm S D$ & $33.1 \pm 18.0$ & $41.8 \pm 20.7$ & $<0.0001$ \\
\hline Age over 50 yrs old, n (\%) & $175(20.4)$ & $50(38.5)$ & $<0.0001$ \\
\hline \multicolumn{4}{|l|}{ Sex } \\
\hline Male, n $(\%)$ & $457(53.4)$ & $70(53.9)$ & 0.9222 \\
\hline \multicolumn{4}{|l|}{ ASA class } \\
\hline 1 & $511(59.7)$ & $53(40.8)$ & $<0.0001$ \\
\hline 2 & $335(39.1)$ & $64(49.2)$ & 0.0289 \\
\hline$\geq 3$ & $10(1.2)$ & $13(10)$ & $<0.0001$ \\
\hline Length of hospital stay (day), mean \pm SD & $4.0 \pm 2.4$ & $6.3 \pm 4.4$ & $<0.0001$ \\
\hline WBC count (on admission) & $12,909 \pm 5,865$ & $12,726 \pm 4,824$ & 0.6952 \\
\hline Night hospital visit, $n(\%)$ & $143(16.7)$ & $29(22.3)$ & 0.1168 \\
\hline Night admission, $n(\%)$ & $185(21.6)$ & $32(24.6)$ & 0.4412 \\
\hline Night operation, n $(\%)$ & $33(3.9)$ & $4(3.1)$ & 0.6635 \\
\hline Operation time (min) & $54.8 \pm 24.7$ & $79.1 \pm 34$ & $<0.0001$ \\
\hline Visit-to-operation (hr), Mean \pm SD & $9.2 \pm 5.6$ & $11 \pm 6.3$ & 0.001 \\
\hline \multicolumn{4}{|l|}{ Visit-to-operation, n (\%) } \\
\hline Within $6 \mathrm{hr}$ & 322 (37.62) & $31(23.85)$ & 0.0023 \\
\hline $6 \sim 12 \mathrm{hr}$ & 308 (35.98) & $50(38.46)$ & 0.5837 \\
\hline $12 \sim 24 \mathrm{hr}$ & $212(24.77)$ & 46 (35.38) & 0.0103 \\
\hline Over $24 \mathrm{hr}$ & $14(1.64)$ & $3(2.31)$ & 0.4814 \\
\hline \multicolumn{4}{|l|}{ Visit-to-operation, n (\%) } \\
\hline Within $12 \mathrm{hr}$ & $630(73.60)$ & 81 (62.31) & 0.0075 \\
\hline Over $12 \mathrm{hr}$ & $226(26.40)$ & 49 (37.69) & \\
\hline Laparoscopic appendectomy, n (\%) & $853(99.7)$ & $125(96.2)$ & 0.0015 \\
\hline Open conversion, n $(\%)$ & $2(0.2)$ & $5(3.9)$ & $<0.0001$ \\
\hline Drain insertion & $174(20.3)$ & $87(66.9)$ & $<0.0001$ \\
\hline
\end{tabular}


Table 3. Complications overall and comparison between 'non-perforated' and 'perforated' groups

\begin{tabular}{|c|c|c|c|c|c|}
\hline Outcomes & $\begin{array}{c}\text { Total } \\
(\mathrm{N}=986)\end{array}$ & $\begin{array}{l}\text { Non-perforation } \\
\quad(\mathrm{N}=856)\end{array}$ & $\begin{array}{l}\text { Perforation } \\
(\mathrm{N}=130)\end{array}$ & $\begin{array}{c}\text { OR } \\
(95 \% \mathrm{Cl})\end{array}$ & $p$ value \\
\hline Mortality & 0 & 0 & 0 & - & - \\
\hline SSI, n $|\%|$ & $43(4.36)$ & $33(3.86)$ & 10 (7.69) & $2.08(1 \sim 4.33)$ & 0.050 \\
\hline Wound infection, $n(\%)$ & $30(3.04)$ & $24(2.8)$ & $6(4.62)$ & $1.68(0.67 \sim 4.19)$ & 0.268 \\
\hline Intra-abdominal abscess, n (\%) & $13(1.32)$ & $9(1.05)$ & 4 (3.08) & $2.99(0.91 \sim 9.85)$ & 0.072 \\
\hline Stump appendicitis, n (\%) & $2(0.2)$ & $2(0.23)$ & $0(0)$ & $<0.001 \mid<0.001 \sim>999.9)$ & 0.988 \\
\hline |leus, n $(\%)$ & $8(0.81)$ & $3(0.35)$ & $5(3.85)$ & $11.37(2.69 \sim 48.17)$ & 0.001 \\
\hline Intra-abdominal fluid collection, n $|\%|$ & $8(0.81)$ & $5(0.58)$ & $3(2.31)$ & $4.03(0.95 \sim 17.05)$ & 0.059 \\
\hline Intervention, n (\%) & $6(0.61)$ & $4(0.47)$ & $2(1.54)$ & $3.33(0.6 \sim 18.36)$ & 0.168 \\
\hline Readmission, n (\%) & $16(1.62)$ & $12(1.4)$ & 4 (3.08) & $2.23(0.71 \sim 7.03)$ & 0.170 \\
\hline Reoperation, n $|\%|$ & $3(0.3)$ & $1(0.12)$ & $2(1.54)$ & $13.36(1.2 \sim 148.39)$ & 0.035 \\
\hline Hydronephrosis, n (\%) & $1(0.1)$ & $1(0.12)$ & $0(0)$ & $<0.001(<0.001 \sim>999.9)$ & 0.987 \\
\hline Sepsis, n (\%) & $1(0.1)$ & $0(0)$ & $1(0.77)$ & $>999.9(<0.001 \sim>999.9)$ & 0.980 \\
\hline
\end{tabular}

Table 4. Predictors of perforated appendicitis after logistic regression

\begin{tabular}{lcc}
\hline \multicolumn{1}{c}{ Factor } & Adjusted OR (95\% CI) & $p$ value \\
\hline Age & $1(0.99 \sim 1.02)$ & 0.592 \\
\hline Male sex & $1.06(0.69 \sim 1.63)$ & 0.795 \\
\hline ASAclass 3 & $3.77(1.14 \sim 12.43)$ & 0.029 \\
\hline Operation time (min) & $1.01(1.01 \sim 1.02)$ & 0.000 \\
\hline $\begin{array}{l}\text { Visit-to-operation (each 1-h increase) } \\
\text { Visit-to-operation time }\end{array}$ & $1.04(1 \sim 1.07)$ & 0.043 \\
$\quad$ Within 12 hr & $0.59(0.40 \sim 0.87)$ & 0.008 \\
$\quad$ Over 12 hr & & \\
\hline
\end{tabular}

$(p<0.0001)$ in non-perforation and perforation groups, respectively. The proportion of patients older than 50 years was $20.4 \%$ and, $38.4 \%(p<0.0001)$ and the percentage of patients who were classified as ASA class 2 or 3 was $40.3 \%$ and, 59.2\% $(p<0.0001)$, respectively, in each group. The mean hospitalization period in each group was $4 \pm 2.4$ and, $6.3 \pm 4.4$ days, respectively $(p<0.0001)$.

The mean operation time was $54.8 \pm 24.7$ minutes and 79.1 \pm 34.0 minutes, respectively. Patients who underwent surgery more than 12 hours after hospital visit included $26.4 \%$ of the non-perforation group patients and $37.7 \%$ of the perforation group patients $(p=0.0075)$. Also, the mean hospital visitto-operation time was $9.2 \pm 5.6,11 \pm 6.3$ hours, respectively in non-perforation group and perforation group $(p<0.0001)$. Open conversion was conducted in $0.2 \%$ of non-perforation group patients and in $3.9 \%$ of perforation group patients $(p<0.0001)$.
The drain insertion rate was $20.3 \%$ in non-perforation group and $67 \%$ in perforation group $(p<0.0001)$ (Table 2). The SSI rate was $3.86 \%$ in non-perforation group, $7.69 \%$ in perforation group, respectively. Ileus rate was $0.35 \%$ in non-perforation group, 3.85\% in perforation group, respectively. Other complications such as intra-abdominal abscess, intra-abdominal fluid collection, intervention, readmission, reoperation, hydronephrosis, or sepsis were not significantly different in both groups (Table 3).

\section{Predictors of perforated appendicitis after logistic regression analysis}

Using logistic regression analysis, several factors were identified as predictors of perforated appendicitis: the operation time [odds ratio (OR) (95\% confidence interval) $(95 \% \mathrm{CI}), 1.01$ (1.01 1.02); $p=0.001]$ and, hospital visit-to-operation time [OR (95\% CI), 1.04 (1 1.07); $p=0.043$ ] were identified as predictors, and every hour increase between the time from Emergency Department triage and the time of appendectomy was independently associated with an increase in odds of perforation by 4\% ( $p=0.04$; adjusted OR, 1.04; 95\% CI, 1.00 1.07; Table 4).

\section{Characteristics of the patients 'with' or 'without' SSI}

When we compared between the patients with SSI and without SSI, there were no significant differences in age, sex, ASA class, or WBC count between two groups. On the other hand, a longer operation time was significantly associated with the occurrence of SSI $(74 \pm 30.1$ minutes vs. $57.3 \pm$ 
Table 5. Characteristics of the patients 'with' or 'without' SSI

\begin{tabular}{|c|c|c|c|}
\hline Variable & No SSI (N=943) & $\mathrm{SSI}(\mathrm{N}=43)$ & $p$ value \\
\hline Age lyears), mean $\pm S D$ & $34.1 \pm 18.5$ & $36.21 \pm 20.4$ & 0.4771 \\
\hline Age over 50 yrs old, $n(\%)$ & $212(22.5)$ & $13(30.2)$ & 0.2362 \\
\hline \multicolumn{4}{|l|}{ Sex } \\
\hline Male, n $(\%)$ & $500(53.0)$ & $27|62.8|$ & 0.2092 \\
\hline \multicolumn{4}{|l|}{ ASA class } \\
\hline 1 & $545(57.8)$ & $19(44.2)$ & 0.0778 \\
\hline 2 & 376 (39.9) & $23(53.5)$ & 0.0753 \\
\hline$\geq 3$ & $22(2.3)$ & $1(2.3)$ & 0.9975 \\
\hline Length of hospital stay (days), mean $\pm S D$ & $4.3 \pm 2.8$ & $5 \pm 4.2$ & $<0.0001$ \\
\hline WBC count (on admission) & $12,918 \pm 5,808$ & $12,169 \pm 3,821$ & 0.2271 \\
\hline Night hospital visit, n $(\%)$ & $160(17)$ & $12(28)$ & 0.0645 \\
\hline Night admission, $n(\%)$ & $206(21.9)$ & $11(25.6)$ & 0.563 \\
\hline Night operation, n $(\%)$ & $36(3.8)$ & $1(2.3)$ & 0.6146 \\
\hline Operation time (min) & $57.3 \pm 27$ & $74 \pm 30.1$ & $<0.0001$ \\
\hline Visit-to-operation time (hr), mean $\pm S D$ & $9.5 \pm 5.8$ & $9.2 \pm 5.1$ & 0.7642 \\
\hline \multicolumn{4}{|l|}{ Visit-to-operation time, $\mathrm{n}(\%)$} \\
\hline Within $6 \mathrm{hr}$ & $336(35.63)$ & 17 (39.53) & 0.6015 \\
\hline $6 \sim 12 \mathrm{hr}$ & $345(36.59)$ & $13(30.23)$ & 0.3969 \\
\hline $12 \sim 24 \mathrm{hr}$ & 245 (25.98) & $13(30.23)$ & 0.5351 \\
\hline Over $12 \mathrm{hr}$ & $17(1.8)$ & $0(0)$ & 0.3745 \\
\hline Laparoscopic appendectomy, n (\%) & 936 (99.3) & $42(97.7)$ & 0.2577 \\
\hline Open conversion, n $(\%)$ & $6(0.6)$ & $1(2.3)$ & 0.1969 \\
\hline Drain insertion & $244(25.9)$ & $17(39.5)$ & 0.0471 \\
\hline Perforation & $120(12.7)$ & $10(23.3)$ & 0.0459 \\
\hline
\end{tabular}

Table 6. Predicting factors of SSI development after logistic regression analysis

\begin{tabular}{|lcc|}
\hline \multicolumn{1}{c}{ Factor } & Adjusted $\mathrm{OR}(95 \% \mathrm{CI})$ & $p$ value \\
\hline Age & $1.00(0.98 \sim 1.02)$ & 0.862 \\
\hline Male sex & $1.47(0.77 \sim 2.80)$ & 0.229 \\
\hline Operation time (min) & $1.01(1.00 \sim 1.02)$ & 0.004 \\
\hline $\begin{array}{l}\text { Visit-to-operation time } \\
\text { (each 1-hr increase) }\end{array}$ & $0.99(0.93 \sim 1.05)$ & 0.796 \\
\hline Drain insertion & $1.14(0.46 \sim 2.31)$ & 0.755 \\
\hline Perforation & $1.43(0.62 \sim 3.27)$ & 0.403 \\
\hline
\end{tabular}

27, in SSI and non-SSI groups, respectively; $p<0.0001$ ). Also, the occurrence of SSI was increased significantly with drain insertion ( $39.5 \%$ vs. $25.9 \%$, respectively; $p=0.0471$ ). The presence of perforation higher in SSI group as two-fold regardless of the timing of appendectomy (23.3\% vs. $12.7 \%$, respectively; $p=0.0459$ ). Mean hospital visit-to-operation time in SSI group was lower than visit-to-operation time in No SSI group (9.2 vs. $9.5 \%$, respectively. $p=0.7642$ ), but this difference was not statistically significant (Table 5).

\section{Predicting factors of the SSI after logistic regression analysis}

After logistic regression analysis, operation time was the only factor that was found to significantly increase SSI risk with every minute [OR (95\% CI), 1.01 (1.00 1.02); $p=0.004]$, 
after adjusting for age, sex, hospital visit to operation time, drain insertion and presence of appendiceal perforation (Table 6).

In stratification analysis, there was no significant difference in the SSI rate between the hospital visit-to-operation and SSI.

\section{DISCUSSION}

Acute Appendicitis (AA) is one of the most common disease in emergency clinics. ${ }^{1-7}$ In this study, we analyzed appendectomy timing as a risk factor of complications of appendicitis, especially perforation and SSI. We demonstrated that a delay of more than 12 hours before appendectomy was significantly associated with an increased risk of perforation of the appendix.

Patients whose appendix perforated while waiting for appendectomy in hospital had much greater morbidity rates. Perforation was significantly associated with a higher re-intervention rate, conversion rate, and longer length of hospital stay (LOS). Specifically, some authors have previously hypothesized that increasing time delay before surgical intervention concomitantly increases perforation risk. Therefore, many surgeons have stated that appendectomy should be performed without delay. ${ }^{8-13}$ Busch et al. found that there was a significantly higher rate of perforation when comparing rates between patients whose appendectomy timing was greater than 12 hours versus those whose timing was less than 12 hours after visit to hospital. ${ }^{11}$ Bonadio et al. also concluded that an inhospital delay of more than 9 hours from Emergency Department visit to the operating room (OR) was associated with an approximately six-fold greater risk for developing appendiceal perforation in children. ${ }^{12}$

However, several recently published retrospective series have reported conflicting relationships between delayed appendectomy and the risk of complications. Eko et al. assessed the effects of time delay to the OR for uncomplicated acute appendicitis and found that timing of surgery did not affect the incidence of perforation when comparing patients who had a time to the OR of less than 18 hours to patients with a greater than 18 hour time delay from the hospital visit. ${ }^{14}$ Some studies reported that time delay before appendectomy in children did not increase the rate of histopathologic perforation. ${ }^{26}$

Our data showed that patients with appendiceal perforation required a significantly longer hospitalization period and a greater number of radiographic imaging procedures during hospitalization. One of the interesting findings of this study is the fact that delayed appendectomy was associated with a significant increase in perforation rates, whereas no such negative effect was observed in the rate of SSI.
Univariate analysis showed a significant difference in visitto-operation time within 12-hrs between perforation group and non-perforation group. This cut-off has been used in several prior studies; thus, we can compare the results of these studies directly. ${ }^{11}$ Multivariable analysis also showed statically significant results. This study revealed that in-hospital delays prior to appendectomy are associated with a significantly higher perforation rate. The hospital visit-to-operation delay increased the perforation rate in every hour statistically, especially when the delay was greater than 12 hours.

In addition, we evaluated the relationship between the timing of appendectomy and SSI rates. In some previous articles including studies by Burjonrappa et al. and Teixeira et al., an increased risk of SSI was associated with delayed appendectomy timing. ${ }^{15,27}$ However, we could not find any relationship between appendectomy timing and SSI rates.

In conclusion, an increased in-hospital time delay from the Emergency Department to the OR is associated with an increased risk of perforation, especially in patients with a greater than 12-hour delay in hospital visit-to-operation among those patients who presented with radiologically confirmed non-perforated appendicitis preoperatively.

However, this study has limitations that these conclusions are derived from retrospective, single-centered, uncontrolled data. A prospective, multi-centered, randomized controlled study is needed to generalize our results.

\section{REFERENCES}

1) Williams GR. Presidential Address: a history of appendicitis. With anecdotes illustrating its importance. Ann Surg 1983;197:495-506.

2) FITZ R. On perforating inflammation of the vermiform appendix with special reference to its early diagnosis and treatment. N Engl J Med 1935;213:245-248.

3) Addiss DG, Shaffer N, Fowler BS, Tauxe RV. The epidemiology of appendicitis and appendectomy in the United States. Am J Epidemiol 1990;132:910-925.

4) Ceresoli M, Zucchi A, Allievi N, et al. Acute appendicitis: Epidemiology, treatment and outcomes- analysis of 16544 consecutive cases. World J Gastrointest Surg 2016;8:693-699.

5) Sulu B. Demographic and Epidemiologic Features of Acute Appendicitis In: Lander A, editor. Appendicitis - A Collection of Essays from Around the World. Rijeka: INTECH; 2012. p.169-178.

6) Hale DA, Jaques DP, Molloy M, Pearl RH, Schutt DC, d'Avis JC. Appendectomy. Improving care through quality improvement. Arch Surg 1997;132:153-157.

7) Sleem R, Fisher S, Gestring M, et al. Perforated appendicitis: is early laparoscopic appendectomy appropriate? Surgery 2009;146:731-737; discussion 737-738.

8) Papandria D, Goldstein SD, Rhee D, et al. Risk of perforation 
increases with delay in recognition and surgery for acute appendicitis. J Surg Res 2013;184:723-729.

9) Meltzer JA, Kunkov S, Chao JH, et al. Association of Delay in Appendectomy With Perforation in Children With Appendicitis. Pediatr Emerg Care 2016 Sep 30 [Epub]. DOI:10.1097/ pec.0000000000000850.

10) Harmon LA, Davis ML, Jupiter DC, Frazee RC, Regner JL. Computed tomography to operating room in less than 3 hours minimizes complications from appendicitis. Am J Surg 2016;212:246250.

11) Busch M, Gutzwiller FS, Aellig S, Kuettel R, Metzger U, Zingg U. In-hospital delay increases the risk of perforation in adults with appendicitis. World J Surg 2011;35:1626-1633.

12) Bonadio W, Brazg J, Telt N, et al. Impact of In-Hospital Timing to Appendectomy on Perforation Rates in Children with Appendicitis. J Emerg Med 2015;49:597-604.

13) Al-Qurayshi Z, Kadi A, Srivastav S, Kandil E. Risk and outcomes of 24-h delayed and weekend appendectomies. J Surg Res 2016;203:246-252.e241.

14) Eko FN, Ryb GE, Drager L, Goldwater E, Wu JJ, Counihan TC. Ideal timing of surgery for acute uncomplicated appendicitis. $\mathrm{N}$ Am J Med Sci 2013;5:22-27.

15) Teixeira PG, Sivrikoz E, Inaba K, Talving P, Lam L, Demetriades D. Appendectomy timing: waiting until the next morning increases the risk of surgical site infections. Ann Surg 2012;256:538-543.

16) Kim HK, Kim YS, Lee SH, Lee HH. Impact of a Delayed Laparoscopic Appendectomy on the Risk of Complications in Acute Appendicitis: A Retrospective Study of 4,065 Patients. Dig Surg 2017;34:25-29.

17) Mak GZ, Loeff DS. Paradigm Shifts in the Treatment of Appendicitis. Pediatr Ann 2016;45:e235-240.
18) Yardeni D, Hirschl RB, Drongowski RA, Teitelbaum DH, Geiger JD, Coran AG. Delayed versus immediate surgery in acute appendicitis: do we need to operate during the night? J Pediatr Surg 2004;39:464-469; discussion 464-469.

19) Shin CS, Roh YN, Kim JI. Delayed appendectomy versus early appendectomy in the treatment of acute appendicitis: a retrospective study. World J Emerg Surg 2014;9:8.

20) Drake FT, Mottey NE, Farrokhi ET, et al. Time to appendectomy and risk of perforation in acute appendicitis. JAMA Surg 2014;149:837-844.

21) Chen CC, Ting CT, Tsai MJ, et al. Appendectomy timing: Will delayed surgery increase the complications? J Chin Med Assoc 2015;78:395-399.

22) Kim SH, Park SJ, Park YY, Choi SI. Delayed Appendectomy Is Safe in Patients With Acute Nonperforated Appendicitis. Int Surg 2015;100:1004-1010.

23) Ingraham AM, Cohen ME, Bilimoria KY, et al. Effect of delay to operation on outcomes in adults with acute appendicitis. Arch Surg 2010;145:886-892.

24) Kim M, Oh ST. Effect of time delays for appendectomy as observed on computed tomography in patients with noncomplicated appendicitis. Am J Emerg Med 2016;34:167-169.

25) Abou-Nukta F, Bakhos C, Arroyo K, et al. Effects of delaying appendectomy for acute appendicitis for 12 to 24 hours. Arch Surg 2006;141:504-506; discussioin 506-507.

26) Almstrom M, Svensson JF, Patkova B, Svenningsson A, Wester T. In-hospital Surgical Delay Does Not Increase the Risk for Perforated Appendicitis in Children: A Single-center Retrospective Cohort Study. Ann Surg 2017;265:616-621.

27) Burjonrappa S, Rachel D. Pediatric appendectomy: optimal surgical timing and risk assessment. Am Surg 2014;80:496-499. 